\title{
Escala Trifatorial da Identidade Social (ETIS): Evidências de sua Adequação Psicométrica
}

\author{
Thiago Gomes Nascimento - Instituto Superior de Ciências Policiais e do Centro Universitário, Brasília, Brasil \\ Eda Castro Lucas de Sonza - Universidade de Brasilia, Brasilia, Brasil
}

\begin{abstract}
Resumo
Este artigo objetivou verificar evidências psicométricas (validade e precisão) de adequação da Escala Trifatorial da Identidade social (ETIS) ao contexto profissional, realizando-se dois estudos. No Estudo 1, participaram 465 policiais militares do DF, a maioria do sexo masculino (88\%), com idade média de 38,78 ( $D P=7,08)$. Eles responderam a ETIS e perguntas demográficas. A análise dos componentes principais indicou a estrutura trifatorial, cujos alfas de Cronbach foram 0,83 (centralidade), 0,82 (afeto) e 0,86 (laços). No Estudo 2, participaram 451 policiais militares do DF, a maioria do sexo masculino (88,7\%), com idade média de 39,25 $(D P=6,73)$. Testou-se a estrutura trifatorial por meio de análise fatorial confirmatória. Os indicadores de ajuste foram satisfatórios $\left(\mathrm{X}^{2} / g l=2,67 ; \mathrm{CFI}=0,98 ; \mathrm{GFI}=0,98\right.$; RMSEA = 0,061). A confiabilidade, medida pelo Rho de Jöreskog, mostrou-se adequada, sendo 0,87 (centralidade), 0,87 (afeto) e 0,91 (laços). Os indicadores do estudo exploratório e confirmatório demonstraram adequações psicométricas satisfatórias. Por fim, a ETIS mostrou validade convergente e discriminante para o contexto profissional.

Palavras-chave: teoria da identidade social, identidade profissional, instrumento de medida, polícia, validade
\end{abstract}

Three-Factor Scale of Social Identity: Evidence of its Psychometric Adequacy

\begin{abstract}
The objective of this study was to verify empirical evidence of the psychometric (validity and reliability) adequacy of the ThreeFactor Scale of Social Identity (ETIS), based on two studies. The sample in study 1 was composed by 465 military policemen from the Brazilian Federal District, $88 \%$ male, with mean age of 38.78 years $(\mathrm{SD}=7.08)$. They filled the questionnaire with the ETIS and demographic questions. Using a Principal Components Analysis, a three-factor structure was observed, with Cronbach's alphas of 0.83 (centrality), 0.82 (affect) and 0.86 (ties). The sample in study 2 was composed by 451 military policemen from the Brazilian Federal District, $88.7 \%$ male with a mean age of 39.25 years $(\mathrm{SD}=6.73)$. The three-factor structure was tested through Confirmatory Factor Analysis. The adjustment indexes were satisfactory $\left(\mathrm{X}^{2} / \mathrm{g} .1 .=2.67 ; \mathrm{CFI}=0.98\right.$; $\mathrm{GFI}=0.98$; RMSEA=0.061). Reliability, measured by Jöreskog's Rho, was adequate, being 0.87 (centrality), 0.87 (affect), and 0.91 (ties). The indicators of the exploratory and confirmatory study demonstrated satisfactory psychometric adequacy. Finally, ETIS showed convergent and discriminant validity for the professional context.

Keywords: Social Identity Theory; Professional Identity; Measuring Instrument; Police; validity.
\end{abstract}

Escala de los Tres Factores de la Identidad Social: Evidencias de su Adecuación Psicométrica

\begin{abstract}
Resumem
El objetivo de este artículo fue verificar evidencias psicométricas de adecuación (validez y precisión) en la Escala de Tres Factores de Identidad Social (ETIS), llevándose a cabo dos estudios. En el primer estudio participaron 465 policías militares del Distrito Federal, la mayoría de sexo masculino (88\%) con edad media de 38,78 (DP = 7,08). Ellos respondieron la ETIS y preguntas demográficas. El análisis de los componentes principales indicó la estructura tri-factorial, cuya alfa de Cronbach fue 0,83 (centralidad), 0,82 (afecto) y 0,86 (lazos). En el segundo estudio participaron 451 policías militares del Distrito Federal, $88,7 \%$ hombres, con edad media de 39,25 (DP = 6,73). Se comprobó la estructura tri-factorial por medio de análisis factorial confirmatorio. Los indicadores de ajuste fueron satisfactorios $\left(\mathrm{X}^{2} /\right.$ g.l. $=2,67$; CFI = 0,98; GFI = 0,98; RMSEA = 0,061). La confiabilidad, medida por Rho Jöreskog, fue adecuada, siendo 0,87 (centralidad), 0,87 (afecto) y 0,91 (lazos). Los indicadores del estudio exploratorio y confirmatorio demostraron adecuaciones psicométricas satisfactorias. Por último, la ETIS mostró validez convergente y discriminante para el contexto profesional.

Palabras-clave: Teoría de Identidad Social; Identidad profesional; Instrumento de medida; Policía; Validez.
\end{abstract}

A perspectiva social da identidade tem assumido papel proeminente nas pesquisas sobre comportamento de grupo e relações intergrupais (Cameron, 2004; Nascimento, 2014), notadamente nos últimos 30 anos, com a consolidação da identidade social como construto relevante em investigações de diferentes áreas. Como, por exemplo, no contexto profissional (Kira \& Balkin, 2014; Nascimento, Torres \& Adaid-Castro, 2015).
Dois fatores, de acordo com Cameron (2004), são os responsáveis pela proeminência da identidade social. O primeiro reflete o significado teórico atribuído a identificação social pela Teoria Identidade Social - TIS (Tajfel, 1978; Tajfel \& Turner, 1979), que propõe uma extensão mais social da teoria da comparação social de Festinger (1971). O segundo fator refere-se à existência de medidas de identidade social. 
No contexto internacional, a medida mais utilizada de identificação social foi desenvolvida por Brown et al. (1986), denominada escala de identidade de grupo, cuja tendência é mostrar a identidade social com uma única dimensão, com resultados analíticos do fator denotando direcionalidade do item em vez de dimensionalidade do construto (Brown et al., 1986; Kelly, 1988; Obst \& White, 2005). Evidências, entretanto, ocorrem no sentido de mensurar identidade social de forma multidimensional, com três fatores advindos da TIS, apresentando-se, assim, uma medida mais robusta, apropriada e útil (Cameron \& Lalonde, 2001; Ellemers et al., 1999; Obst \& White, 2005).

Diante disso, o presente artigo tem como objetivo buscar evidências psicométricas (validade e consistência interna) de adequação da Escala Trifatorial da Identidade social (ETIS) ao contexto profissional brasileiro, originalmente construída e validada por Cameron (2004). A análise das evidências de sua validade fatorial, validade convergente e discriminante, sua homogeneidade e consistência interna serão de fundamental importância à investigação da generalidade dessa escala, aplicando-a a amostras distintas de sua validação original, e permitirá identificar se há invariância fatorial.

\section{A Teoria da Identidade Social}

Os estudos sobre a identidade social, no campo de abrangência da Psicologia Social, encontram em Henri Tajfel um de seus principais teóricos (Galinkin \& Zauli, 2011). A definição proposta por Tajfel (1978) para identidade social inicia-se pelo autoconceito, que deriva da pertença a um ou mais grupos, associado ao valor e ao significado emocional que tal agregação traz para a pessoa. Essa definição tem como propósito abranger os efeitos da natureza e a importância subjetiva do comportamento dos indivíduos em suas relações interpessoais (Tajfel, 1978, 1982), mesmo admitindo os limites da definição e a complexidade da forma como o indivíduo se enxerga em relação ao ambiente físico e social. A estrutura da TIS (Tajfel, 1982; 1983; Tajfel \& Turner, 1979) parte da ligação de três conceitos essenciais: categorização social, identidade social e comparação social.

Categorização social é revelada como um instrumento que segmenta, classifica e ordena o ambiente social, servindo como um sistema de orientação que ajuda a criar e definir o lugar do indivíduo na sociedade. Assim, os grupos sociais contribuem para a construção da identidade social dos seus membros, sendo a sociedade responsável não só pela definição, mas, também, pela criação da realidade psicológica (Tajfel, 1983). A identificação grupal é um construto cognitivo, ou um processo cognitivo básico (Galinkin \& Zauli, 2011), que se liga à aquisição de conhecimento por intermédio da percepção do indivíduo. Em seguida ao processo de identificação grupal, o indivíduo assume os sucessos e fracassos desse grupo, o que acarreta prazeres e sofrimentos (Torres \& Pérez-Nebra, 2004).

Assim, o componente cognitivo refere-se à autocategorização e à autodefinição do sujeito, ou seja, ao instituir um senso de pertencimento a determinado grupo ou categoria social, o indivíduo tende a assumir seus protótipos e estereótipos, vindo a expressar moldes e atributos responsáveis pela caracterização e distinção de um grupo frente aos demais (Fernandes, Marques, \& Carrieri, 2009). Nessa dimensão, constituem-se as crenças, as atitudes, os sentimentos e o comportamento dos membros dos grupos, maximizando as similaridades e as diferenças entre os mesmos (Hogg \& Terry, 2000; Howard, 2000).

A identidade social é, em larga medida, relacional e comparativa, o que gera determinadas consequências ao nível de pertença de grupo (Tajfel, 1983). A primeira, diz respeito a um indivíduo manter-se em um grupo e buscar novos grupos que, gerando satisfação, contribuam para alguns aspectos da sua identidade. Se ao contrário, o grupo não preencher esse requisito, o indivíduo tenderá a abandoná-lo, a não ser que seja impossível, por razões objetivas ou, por colocar em conflito valores importantes. $O$ fato de abandonar o grupo, ocasiona duas soluções possíveis: mudar a interpretação individual dos atributos do grupo, de modo que suas características indesejáveis se tornem justificáveis, ou aceitáveis por meio de reinterpretação; aceitar a situação tal como é e empenhar-se na ação social que possa levar às mudanças desejáveis na situação (Tajfel, 1983).

Os sentimentos que os indivíduos estabelecem ao fato de pertencerem a determinado grupo social retratam o componente afetivo, incorporado ao componente cognitivo do processo de identificação social. A maior percepção atribuída às similaridades, equivalências, intenções e aos comportamentos, propiciadas pela comparação com outros grupos, ocasiona a tendência de o sujeito manter-se como membro do grupo que lhe proporcione uma autodefinição positiva (Fernandes et al. 2009). De outra forma, características do grupo que afetem de forma negativa a autodefinição do sujeito ocasionam o seu desligamento do grupo, passando a se 
condicionar pela permeabilidade dos limites do grupo social, tendo como alternativa desenvolver estruturas de aceitação (Reade, 2001; Tajfel, 1981).

Outra consequência do reconhecimento da identidade em termos socialmente definidos leva em conta que nenhum grupo vive sozinho em determinada sociedade, resultando, disso, que a reinterpretação dos atributos e o empenho na ação social só fará sentido quando ocorrer a comparação com outros grupos. Os indivíduos, segundo a TIS, buscam uma identificação social positiva no procedimento de comparação com outros grupos. Logo, surge a necessidade de uma identidade pessoal e de uma identidade social positiva, o que representa pertencer a grupos valorizados socialmente (Galinkin \& Zauli, 2011).

$\mathrm{Na}$ percepção do sujeito, o componente valorativo é atrelado à maneira como se estabelece a valorização de seu grupo social pelos outros grupos, o que pode ser positiva ou negativa, demonstrando o valor e o prestígio do seu grupo social, bem como, a crítica dos demais grupos (Fernandes et al., 2009). O componente valorativo implica na intensa motivação para os membros do grupo assumirem comportamentos causadores de uma percepção positiva (Reade, 2001; Tajfel, 1981). Em vista disso, ocorre acentuada propensão de os sujeitos compartilharem valores, crenças, normas e regras dos grupos e das organizações consideradas detentoras de maior prestígio, o que poderia afetar de forma positiva a sua autoestima e autodefinição (Ashforth, 2001; Corley \& Gioia, 2004; Hogg \& Terry, 2000).

O último conceito pilar da TIS trata da comparação social, que se estabelece na medida em que dois ou mais indivíduos, que compartilham uma identificação social comum, consideram a si mesmos como pertencendo à mesma categoria social. As comparações sociais entre grupos baseiam-se na percepção da legitimidade das relações percebidas entre eles. A identidade social não se estabelece apenas como resultado da pertença a determinados grupos, mas, principalmente da comparação entre os grupos internos e os externos, ou seja, de "um mecanismo causal que determina as relações entre grupos" (Álvaro \& Garrido, 2006, p. 278). Dessa forma, o conceito de identidade social está ligado à necessidade de se obter uma imagem positiva e diferente do grupo próprio, razão pela qual a percepção da ilegitimidade em uma relação transcende os limites da semelhança intergrupo no plano das comparações sociais relevantes, buscando, com isso, as causas da ilegitimidade. Ou, conforme esclarece Tajfel (1983), a percepção da ilegitimidade numa relação intergrupo é social e psicológica, é a alavanca aceitável da ação de mudança social no comportamento intergrupo.

\section{Identidade Social no Contexto Profissional}

Quando o foco da identidade social é direcionado aos estudos organizacionais, por se tratar de um construto multidimensional, outras categorizações têm sido evidenciadas (Machado, 2003). Destaca-se aqui, a identidade profissional (Dubar, 2005, 2009; Sainsaulieu, 1977), compreendida como o modo de elaborar um sentido para si na pluralidade de papéis sociais, bem como, em seu reconhecimento pelos outros indivíduos no contexto do trabalho (Sainsanlieu, 1995), ou, ainda, baseada na configuração eu-nós vinculada ao campo das atividades de trabalho (Dubar, 2005).

Ao desempenhar papéis, ou melhor, pelo seu exercício é que os indivíduos constroem ativamente suas identidades (Baugnet, 1998). No mesmo sentido, os papéis vinculados ao mundo do trabalho compõem uma faceta da estrutura identitária dos indivíduos (Sainsanlieu, 1995), e a empresa apresenta-se como um lugar importante para a socialização dos que nela trabalham. A organização, para Sainsanlieu (1995), apresenta-se como uma instituição de socialização secundária, a qual, depois da escola e da família, modela atitudes, comportamentos, a ponto de produzir uma identidade profissional e social.

A identidade no trabalho processa-se nos níveis afetivo e cognitivo (Machado, 2003). Como o indivíduo está envolto em uma estrutura, forma-se uma espécie de mentalidade coletiva, na qual o indivíduo se conforma, assimila suas regras e normas de comportamento e, assim, estabelece vínculos afetivos com as pessoas com as quais coexiste nesse ambiente. Os significados distorcidos, portanto, são oriundos do processo de identificação por parte dos indivíduos. Isso ocorre principalmente quando no ambiente organizacional os indivíduos têm seus espaços de autonomia restringidos, momento em que existe a possibilidade de conceber os procedimentos de identificação que tenham natureza projetiva, isto é, aqueles em que o indivíduo se projeta no lugar do outro. Nessa busca, realiza-se a destituição do lugar ocupado, ou o de natureza introjetiva e imitativa, perante o qual o indivíduo copia o outro e busca viver a vida do outro.

A identidade profissional constitui, portanto, um importante elemento do processo motivacional, que converge para a construção de uma autoestima positiva. Essa constatação não se vincula apenas à realização do 
trabalho, mas, também, ao domínio social organizacional, o qual é positivamente afetado, levando a maneiras mais criativas de se realizar o trabalho, que integram a subjetividade, a socialização e o trabalho (Machado, 2003), com vistas a serem obtidos melhores desempenhos (Van der Zee et al., 2004). O exame da literatura contempla essa influência da identidade sobre o desempenho dos colaboradores, de um funcionário específico, ou de comportamentos relacionados ao desempenho (He \& Brown, 2013, Mitchell et al., 2011), sendo ainda influenciada pela cultura organizacional (Brickson, 2013; Nascimento, 2014). Além disso, estudos ressaltam o efeito positivo da identidade na criatividade dos funcionários (Brickson, 2013; Hirst, van Dick, \& van Knippenberg, 2009; Madjar et al., 2011), devido ao alinhamento entre os seus próprios interesses e o interesse da organização.

O papel da identidade social em sua vertente profissional ou no trabalho tem sido apresentado em pesquisas com vistas ao seu efeito em equipes interprofissionais (Nishii \& Mayer, 2009), havendo evidências de impacto dessa identidade no desempenho de equipes demograficamente diversas (Van Knippenberg \& Schippers, 2007), bem como, de influência da identidade profissional na interação interprofissional (Fitzgerald \& Teal, 2003), sugerindo mérito na investigação da influência da identidade, vinculado ao desempenho no trabalho (Mitchell et al., 2011).

Por fim, cabe salientar que medidas de identidade social aplicadas ao contexto profissional (identidade profissional) são escassas na literatura brasileira (Nascimento, 2010; Nascimento, Torres, Souza, Nascimento, \& Adaid-Castro, 2013; Nascimento, 2014). Entre essas medidas está a de Nascimento (2010), cujas críticas referem-se ao seu contexto específico de construção e à falta de uma teoria de suporte. Reforçando-se a necessidade de novas medidas, como a proposta neste artigo, que pode suprir importante lacuna de instrumentos que podem aferir a identidade profissional, com sustentação teórica e empírica.

\section{Modelo Trifatorial da Identidade Social e Escala de Identificação Social}

A base teórica para a multidimensionalidade da identidade social deriva da definição de Tajfel (1978) para esse conceito, ou seja, "a parte do autoconceito do indivíduo que deriva de seu conhecimento e de sua filiação em certo grupo social (ou grupos), juntamente com o valor emocional e a importância atribuída a esta sociedade" (p. 63). EsSa definição levou a tentativas de representar os componentes em medidas de identificação.

Como existe suporte teórico (Deaux, 1996; Tajfel, 1978) e empírico (Ellemers et al., 1999; Hinkle et al., 1989) convincentes para a existência de múltiplas dimensões da identidade social, Cameron (2004) observou que parece incerta a extensão em que as variações das estruturas fatoriais entre os estudos são atribuíveis à variação metodológica. Além disso, conforme observou Cameron (2004), nenhum modelo multidimensional da identidade social tinha sido, ainda, sujeito à análise fatorial confirmatória, dentro e entre diferentes grupos sociais, ou sistematicamente validados vis-à-vis a medidas comparáveis de identificação. Diante disso, conclui Cameron (2004) que há como se afirmar quais os componentes de identificação a serem mensurados.

A despeito da importância do construto identificação social, desde aspectos teóricos até empíricos em processos de grupo e relações intergrupais, a questão da dimensionalidade está presente. Nesse sentido, com o objetivo de testar o modelo trifatorial da identidade social, oriundo da teoria da identidade social (Tajfel, 1978), Cameron (2004) propõe a identidade social representada em termos dos três fatores, teorizado por Deaux (1996), uma revisão da literatura sobre identificação social argumentou que os processos cognitivos, de associações emocionais e de interdependência entre os membros do grupo são importantes aspectos do processo de identificação social (para mais detalhes ver Deaux, 1996).

Assim, Centralidade, autocategorização, refere-se ao destaque cognitivo dos membros de um grupo, operacionalizada em termos da frequência com que $o$ grupo vem à mente de seus indivíduos, bem como, da importância subjetiva do grupo de autodefinição; Afetos com o grupo de pertença, que trata da avaliação emocional, englobando a dimensão afetiva; Laços com o grupo de pertença, que demonstra a percepção de semelhança e vínculos com outros membros do grupo, percepção de solidariedade.

Para confirmar aestrutura trifatorial da identidade, medida pela força tridimensional da Escala de Identificação Social (ou de Grupo) proposta por Cameron (2004), cinco estudos foram utilizados. Os itens da Escala de Identificação Social foram constituídos com base: em estudos de Cameron e Lalonde (2001), que desenvolveram uma escala de 28 itens de identificação social, derivados de diferenças de gênero; nos itens de medidas de identidades sociais (Brown et al, 1986; Hinkle et al., 1989) e autoestima coletiva (Luhtanen \& 
Crocker, 1992), bem como, em trabalho anterior sobre a identidade social de mulheres (Gurin \& Markus, 1989; Gurin \& Townsend, 1986).

Posteriormente, essa estrutura tripartite foi replicada na medição de identificação étnica em diversas amostras (Boatswain \& Lalonde, 2000), como, por exemplo, a de Obst, Zinkiewicz e Smith (2002), entre outras. Essas evidências preliminares reforçam o aspecto teórico e empírico presente nos três fatores: centralidade cognitiva, afetos no grupo de pertença e relações no grupo de pertença.

Com o intuito de testar modelos uni, bi e trifatoriais da Escala de Identidade Social, Cameron (2004) utilizou uma escala composta por 18 itens. Os resultados das análises fatoriais confirmatórias asseguram a estrutura trifatorial, sendo que entre os cinco estudos realizados, a escala variou de 11 itens para 15 itens. Os coeficientes de confiabilidades médios nos cinco estudos foram: centralidade $(\alpha=0,73)$, afetos em relação ao grupo de pertença $(\alpha=0,79)$, e laços com o grupo de pertença $(\alpha=0,79)$, sendo que os índices de adequação mostraram-se muito satisfatórios (CFIMédio $=0,91$; GFIMédio $=0,90)$.

Posteriormente, Obst e White (2005) buscaram evidências para a validade de construto do modelo de três fatores da identidade social medida pela Escala de Identificação Social (ou de Grupo) proposta por Cameron (2004) em uma amostra de universitários, em cada um dos três grupos de identidades: sexo, estudante e grupo de interesse autosselecionado pelos participantes (por exemplo, clubes desportivos, grupos de internet, associações profissionais, associações de estudantes, clubes de música, clubes de dança, grupos religiosos, grupos de artesanato, grupos de pais e grupos sociais). Os itens foram modificados de forma consistente em participações em grupos. Para tanto, as autoras utilizaram uma versão com 12 itens, testando estruturas uni, bi e trifatoriais. Os resultados confirmaram a estrutura com três fatores, com índices de confiabilidade aceitáveis variando em cada grupo, respectivamente, sexo $(\mathrm{CFI}=0,901$; GFI $=0,908$; RMSEA $=0,089$; centralidade $-\alpha=0,75$; afeto $-\alpha=0,70$; laços $-\alpha=0,78)$, estudantes (CFI $=0,923$; GFI $=0,912$; RMSEA $=$ 0,077 ; centralidade $-\alpha=0,81$; afeto $-\alpha=0,82$; laços $-\alpha=0,81)$ e grupos de interesse (CFI $=0,915$; GFI $=$ 0,916 ; RMSEA $=0,073$; centralidade $-\alpha=0,85$; afeto $-\alpha=0,80$; laços $-\alpha=0,87$ ).

No contexto brasileiro, não foi encontrado estudo com ênfase nesse modelo, tampouco publicações dedicadas à adaptação da Escala de Identificação Grupo, definida a partir do Modelo Trifatorial da Identidade Social (Cameron, 2004). Nesse sentido, proposta como a de buscar evidências psicométricas de adequação da Escala de Identificação Social, que neste trabalho passa a ser chamada: Escala Trifatorial da Identidade social (ETIS), adaptada ao contexto profissional, apresenta-se relevante para o avanço teórico da área, além de possibilitar a replicação de estudos desenvolvidos em outros contextos e a comparação de resultados. Esses aspectos justificam a realização do presente estudo, cujo principal objetivo foi reunir evidências psicométricas de adequação de uma medida de identidade social ao contexto profissional brasileiro, representando a própria identidade profissional e, mais especificamente, da atividade policial.

Para cumprir esse objetivo dois estudos foram realizados. O primeiro destinado aos procedimentos de adaptação e realização da análise fatorial exploratória (Estudo 1), que se justifica na medida em que não é possível saber se a estrutura trifatorial vai se manter no contexto brasileiro e, o segundo, responsável pela realização da análise fatorial confirmatória das dimensões da identidade social (Estudo 2), como propostas por Cameron (2004).

\section{Método}

Como não é recomendável que as análises exploratória e confirmatória sejam realizadas com o mesmo conjunto de dados (Marôco, 2011), a amostra total, após as adequações para a realização das análises multivariadas, foi dividida aleatoriamente em duas subamostras, utilizando o divisor do banco de dados padrão do SPSS (split file). Assim, foram selecionados aleatoriamente $50,04 \%$ dos respondentes para a fase exploratória $(n=$ $465)$, e 49,96\% para a confirmatória $(n=451)$.

\section{Estudo 1}

Este primeiro estudo teve o objetivo específico de reunir evidências acerca da validade fatorial e consistência interna da Escala deIdentificação Social. Compreendeu uma análise preliminar dessa medida, checando a adequação de se contar com uma estrutura trifatorial para representar o construto identidade social (profissional).

\section{Participantes}

Participaram dessa fase 465 policiais militares do DF, a maioria do sexo masculino (88\%), com alta escolaridade (52,5\% graduados e $25,4 \%$ pós-graduados). 
Pertencentes a todos os níveis hierárquicos da Corporação, com idade variando de 24 a 53 anos $(M=38,78$ e $D P=7,08)$, sendo a maioria casada $(63,7 \%)$, católica $(51,4 \%)$ e com 16,12 anos de serviço em média $(D P=$ $8,63)$. Essa foi uma amostra não probabilística, só participando pessoas que concordaram em colaborar com a pesquisa.

\section{Instrumentos}

Os participantes responderam a um questionário composto por duas partes:

Escala de Identificação Social, rebatizada, neste estudo, para Escala Trifatorial da Identidade Social - ETIS (Cameron, 2004), adaptada ao contexto profissional, refletindo a própria identidade profissional. Como anteriormente descrita, essa medida compõe-se de 18 itens distribuídos em três dimensões correspondentes aos fatores teóricos propostos por Deaux (1996), a saber: (1) centralidade (por exemplo, "Ser um policial é uma parte importante de quem eu sou."); (2) afeto com o grupo de pertença (por exemplo, "Eu não me sinto bem em ser um policial."); (3) laços com o grupo de pertença (por exemplo, "Eu sinto fortes vínculos com outros policiais."). Os itens foram respondidos em uma escala Likert, com os seguintes extremos: $1=D i s$ cordo totalmente e $5=$ Concordo totalmente.

Por fim, com o objetivo de caracterizar os participantes do estudo, foi adicionado um conjunto de perguntas de caráter sociodemográfico (escolaridade, sexo, idade, estado civil, religião, nível hierárquico e tempo de serviço).

\section{Adaptação da Escala}

Esse instrumento foi submetido à adaptação e validação de conteúdo (Cassepp-Borges, Balbinoti \& Teodoro, 2010). O procedimento de tradução da versão original em inglês para o português seguiu a técnica de tradução e retradução de Brislin (1970) e Vallerand (1979). Com vistas a garantir a equivalência da escala em português, optou-se por tradutores bilíngues. Nesse caso, dois doutores em Psicologia brasileiros com vivências nos Estados Unidos e Inglaterra efetuaram traduções independentes, segundo as recomendações de Cha, Kim e Erlen (2007). Posteriormente, outros dois psicólogos, também doutores, bilíngues elaboraram a tradução reversa, ou seja, do português para o inglês. Em seguida, um comitê composto por três estudantes de pós-graduação, um dos membros que realizou a primeira tradução e um membro externo (doutor em Administração) avaliaram cada um dos itens com o objetivo de, levando-se em consideração aspectos da cultura brasileira, aproximar as versões em português e inglês, tendo em conta a versão original em inglês.

Como forma de reduzir os vieses decorrentes do processo de tradução, procedeu-se à validação do conteúdo. Para tanto, utilizou-se o coeficiente da validade de conteúdo (CVC), proposto por Henández-Nieto (2002). Esse coeficiente avalia a concordância entre juízes-avaliadores, mediante o uso de uma escala Likert, que variou de 1 (representa ponquíssimo) a 5 (representa muitíssimo), como forma de investigar a clareza da linguagem, a representatividade (pertinência prática), a relevância teórica dos itens, além da dimensão avaliada, comparando-se a versão adaptada da escala para o português e a sua versão original em inglês. Participaram como juízes avaliadores sete professores, doutores em Psicologia, Sociologia e Administração com domínio na temática do construto.

A análise da dimensão teórica foi realizada comparando a concordância entre os juízes. Por se tratar de uma variável categórica, utilizou-se o coeficiente de kappa médio, calculando-se a média entre os juízes. Foi considerado o critério de Landis e Koch (1977), no qual valores entre $40 \%$ e $60 \%$ indicam uma concordância moderada (TCJ).

A Tabela 1 mostra a escala final, com os escores de CVC para cada item relacionado às três características avaliadas (clareza de linguagem - CL; pertinência prática - PP; e relevância teórica - RT). Além disso, apresenta em qual dimensão teórica foi categorizado o item avaliado pelos sete juízes e pelo autor da escala (DTC).

\section{Procedimentos}

Os questionários foram administrados à Polícia Militar do Distrito Federal (PMDF) no período compreendido entre os meses de março e abril de 2014, sendo aplicados face a face, garantindo o anonimato e o sigilo das respostas, conforme explicitado no TCLE (Termo de Consentimento Livre e Esclarecido). A aplicação foi realizada de forma individual no próprio ambiente de trabalho, em local adequado, para garantir o mínimo de interferência aos respondentes. Em média quinze minutos foram suficientes para a aplicação dos questionários.

\section{Análise de Dados}

As análises foram efetuadas por meio do SPSS Statistics (versão 20), que possibilitou o cálculo dos coeficientes de correlação entre os itens, e a avaliação 
Tabela 1

\begin{tabular}{|c|c|c|c|c|c|c|c|c|}
\hline \multirow[t]{2}{*}{ Item } & \multicolumn{3}{|c|}{$\mathrm{CVC}_{\mathrm{f}}$} & \multicolumn{4}{|c|}{$\begin{array}{c}\text { Dimensão Teórica } \\
\text { (No de juízes-avaliadores) }\end{array}$} & \multirow[b]{2}{*}{ TCJ } \\
\hline & CL & PP & RT & $\mathrm{C}$ & A & $\mathrm{L}$ & DTC & \\
\hline Eu estou contente por ser um policial. & 1 & 0,97 & 0,97 & 0 & 7 & 0 & A & $100 \%$ \\
\hline $\begin{array}{l}\text { Ser um policial é uma parte importante de quem } \\
\text { eu sou. }\end{array}$ & 0,77 & 0,94 & 0,94 & 6 & 0 & 1 & $\mathrm{C}$ & $86 \%$ \\
\hline $\begin{array}{l}\text { Em minha vida diária, eu frequentemente penso } \\
\text { sobre o que significa ser um policial. }\end{array}$ & 0,94 & 0,94 & 0,97 & 7 & 0 & 0 & $\mathrm{C}$ & $100 \%$ \\
\hline $\begin{array}{l}\text { Em um grupo de policiais, eu realmente sinto que } \\
\text { pertenço a esse grupo. }\end{array}$ & 0,94 & 0,94 & 0,97 & 0 & 0 & 7 & $\mathrm{~L}$ & $100 \%$ \\
\hline $\begin{array}{l}\text { Eu encontro dificuldades em formar vínculos } \\
\text { com outros policiais. }\end{array}$ & 0,89 & 0,91 & 0,97 & 0 & 0 & 7 & $\mathrm{~L}$ & $100 \%$ \\
\hline $\begin{array}{l}\text { Eu frequentemente me arrependo de ser um } \\
\text { policial. }\end{array}$ & 0,94 & 0,94 & 0,94 & 1 & 6 & 0 & A & $86 \%$ \\
\hline $\begin{array}{l}\text { Eu frequentemente penso sobre o fato de que } \\
\text { sou um policial. }\end{array}$ & 0,94 & 0,89 & 0,94 & 7 & 0 & 0 & $\mathrm{C}$ & $100 \%$ \\
\hline $\begin{array}{l}\text { Eu não me sinto "conectado" com outros } \\
\text { policiais. }\end{array}$ & 0,89 & 0,94 & 0,94 & 0 & 0 & 7 & $\mathrm{~L}$ & $100 \%$ \\
\hline Eu não me sinto bem em ser um policial. & 0,97 & 0,94 & 0,94 & 0 & 7 & 0 & A & $100 \%$ \\
\hline $\begin{array}{l}\text { Eu normalmente não estou consciente do fato de } \\
\text { que sou um policial. }\end{array}$ & 0,80 & 0,89 & 0,86 & 7 & 0 & 0 & $\mathrm{C}$ & $100 \%$ \\
\hline $\begin{array}{l}\text { Eu realmente me ajusto bem quando estou entre } \\
\text { policiais. }\end{array}$ & 0,89 & 0,91 & 0,97 & 0 & 1 & 6 & $\mathrm{~L}$ & $86 \%$ \\
\hline Eu sinto fortes vínculos com outros policiais. & 0,91 & 0,94 & 0,97 & 0 & 0 & 7 & $\mathrm{~L}$ & $100 \%$ \\
\hline $\begin{array}{l}\text { Eu tenho muito em comum com os demais } \\
\text { policiais. }\end{array}$ & 0,94 & 0,97 & 0,94 & 1 & 1 & 5 & $\mathrm{~L}$ & $71 \%$ \\
\hline $\begin{array}{l}\text { Eu me sinto bem quando eu penso sobre mim } \\
\text { mesmo como um policial. }\end{array}$ & 0,91 & 0,94 & 0,97 & 3 & 4 & 0 & A & $57 \%$ \\
\hline $\begin{array}{l}\text { Ser um policial tem pouco a ver como eu me } \\
\text { sinto sobre mim mesmo. }\end{array}$ & 0,86 & 0,86 & 0,89 & 4 & 2 & 1 & $\mathrm{C}$ & $57 \%$ \\
\hline $\begin{array}{l}\text { O fato de que eu sou um policial raramente entra } \\
\text { em minha mente. }\end{array}$ & 0,83 & 0,94 & 0,94 & 7 & 0 & 0 & C & $100 \%$ \\
\hline $\begin{array}{l}\text { Ser um policial é um importante reflexo de quem } \\
\text { eu sou. }\end{array}$ & 0,91 & 0,97 & 0,97 & 5 & 0 & 2 & C & $71 \%$ \\
\hline $\begin{array}{l}\text { Às vezes tenho sentimentos ruins só de pensar } \\
\text { sobre o fato de que eu sou um policial. }\end{array}$ & 0,83 & 0,94 & 1 & 0 & 7 & 0 & A & $100 \%$ \\
\hline $\mathrm{CVC}_{\mathrm{t}}$ & 0,90 & 0,93 & 0,95 & & & & & \\
\hline
\end{tabular}

Nota. $\mathrm{N}^{\circ}$ : Número da questão; $\mathrm{CVC}_{\mathrm{f}}$ coeficiente de validade de conteúdo para cada item; $\mathrm{CVC}_{\mathrm{t}}$ : Coeficiente Total do Questionário; CL: clareza da linguagem; PP: pertinência prática; RT: relevância teórica; C: centralidade; A: afeto com o grupo de pertença; L: laços com o grupo de pertença; DTC: dimensão teórica proposta por Cameron (2004); TCJ: Taxa de Concordância entre Juízes (\%) sobre a Dimensão Teórica com base na DTC. 
dos indicadores de adequação da matriz correspondente (KMO e Teste de Esfericidade de Bartlett) para a realização de uma análise fatorial. Nesse mesmo software estatístico foram realizadas uma análise de componentes principais, que possibilita revelar a existência ou não de amostras anômalas, de relações entre as variáveis medidas e de relações ou agrupamentos entre amostras (Lyra et al., 2010), bem como, o cálculo da consistência interna (alfa de Cronbach) para os componentes resultantes.

\section{Resultados}

A presente pesquisa buscou evidências psicométricas de adequação da Escala Trifatorial da Identidade social (ETIS) ao contexto profissional, para tanto, verificou-se a pertinência de realizar uma análise fatorial, observando-se indicadores que apoiam esse tipo de análise. Primeiramente, a análise preliminar dos Componentes Principais (PC) e a matriz de intercorrelações mostrou-se fatorizável, como pode ser observado no teste de esfericidade Bartllet $(p<0,000)$ e KMO, que foi de 0,92, considerado maravilhoso (Pasquali, 2012).

Em seguida, foi analisada a dimensionalidade da escala com base em diferentes métodos. O critério de Kaiser identificou até três fatores que explicam 62,18\% da variância total. O primeiro fator é o determinante $(\Delta$ entre o primeiro e o terceiro fatores é de $26,21 \%)$. O teste do screeplot indicou que a ETIS apresenta até três componentes. Por fim, foi realizada a análise paralela de Horn, que identificou até três fatores, conforme Figura 1 e Tabela 2.

Como o método da análise dos componentes principais está particularmente interessado nos componentes mais importantes, aqueles que explicam maior variância, sem, contudo, apresentar um modelo teórico (Pasquali, 2003, 2012), por ser somente um método de simplificação e ortogonalização, recomenda-se a utilização de uma análise fatorial exploratória mais robusta que não uma mera verificação inicial de indicação de fatores (Marôco, 2011). De posse dessas informações, levando-se em conta a versão original da Escala de Identificação Social e a teoria que o fundamenta, decidiu-se realizar uma análise fatorial com a definição dos itens por fator congruente com a proposta de Cameron (2004), assim, procedeu-se à análise

Tabela 2

Autovalores Empíricos e Aleatórios da ETIS

\begin{tabular}{lccc}
\hline \multirow{2}{*}{ Componente } & \multicolumn{2}{c}{ Autovalores iniciais } & \multirow{2}{*}{$\begin{array}{c}\text { Autovalores } \\
\text { aleatórios }\end{array}$} \\
\cline { 2 - 3 } & Total & \% de variância & alc \\
\hline 1 & 6,474 & 35,98 & 1,364 \\
2 & 3,435 & 19,08 & 1,293 \\
3 & 1,283 & 7,20 & 1,239 \\
4 & 0,903 & 5,02 & 1,192 \\
\hline
\end{tabular}

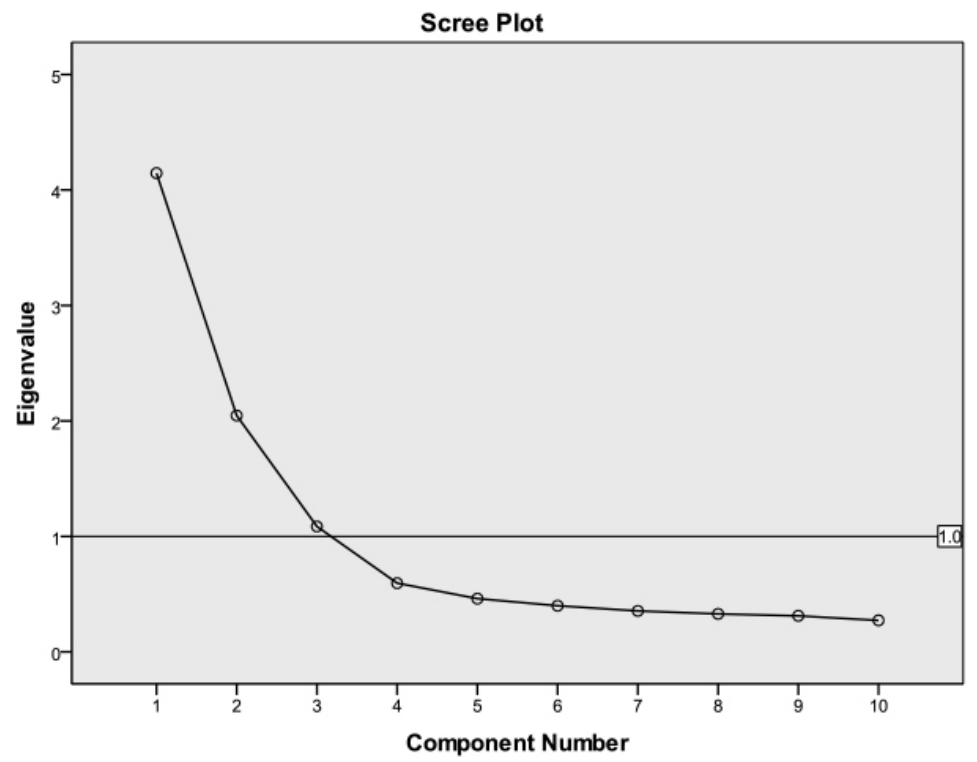

Figura 1. Gráfico do Scree da ETIS. 
fatorial pelo método dos eixos principais $(P A F)$, com rotação Promax, para a extração de três fatores. Foram excluídos os itens que saturaram em mais de um fator (IP5 e IP4), cuja diferença foi inferior a 0,1 (Neiva, Abbad, \& Tróccoli, 2007). Os itens IP1, IP8, IP9, IP11, IP15, IP16 não foram retidos no fator teórico correspondente e, portanto, foram excluídos, para que fosse garantida a retenção de cada item em seu fator correspondente, optou-se também por uma versão mais parcimoniosa do construto, conforme recomendado por Cameron (2004). A nova análise melhorou a representatividade dos itens que passaram a explicar $72,89 \%$ da variância total.

A análise de precisão foi obtida pelos coeficientes alfa de Cronbach e lambda-2 de Guttman, sendo excluídos o item IP7, com vistas a aumentar a confiabilidade do fator (Pasquali, 2012). A estrutura final da ETIS, portanto, reteve nove itens que apresentaram compatibilidades teóricas e parcimônia. A Tabela 3 fornece uma síntese dos resultados finais retidos da análise fatorial exploratória.

Os três fatores da ETIS (laços, afeto e centralidade) estão estruturados de forma bastante satisfatória, representando bem as dimensões teóricas do estudo original (Cameron, 2004).

No Estudo 1, encontrada estrutura semelhante ao modelo teórico/empírico proposto por Cameron (2004), partiu-se para o Estudo 2, no qual são realizados os procedimentos para a realização da análise fatorial confirmatória, como maneira de confirmação da estrutura obtida com a AFE.

\section{Estudo 2}

Nesse segundo, estudo optou-se por realizar análises de natureza confirmatória, procurando complementar o anterior. Especificamente, decidiu-se por checar a estrutura fatorial da Escala Trifatorial da Identidade Social por meio de modelagem por equações estruturais. Esse procedimento favorece conclusão mais incisiva acerca da validade fatorial da medida, bem como, indica o quanto ela se ajusta aos dados empíricos.

\section{Participantes}

Participaram dessa fase 451 policiais militares do DF, a maioria do sexo masculino (88,7\%), com alta escolaridade $(59,9 \%$ graduados e $24,2 \%$ pós-graduados).

Tabela 3

Matriz Fatorial da ETIS

\begin{tabular}{lcccc}
\hline Itens & Fator 1 & Fator 2 & Fator 3 & $\begin{array}{c}\text { Comunalidades } \\
\left(R^{2}\right)\end{array}$ \\
\hline IP13 & 0,94 & & & 0,75 \\
IP14 & 0,85 & & 0,66 \\
IP12 & 0,73 & & 0,64 \\
IP18 & & 0,83 & 0,66 \\
IP6 & & 0,81 & 0,63 \\
IP10 & & 0,75 & 0,54 \\
IP3 & & & 0,69 \\
IP17 & & & 0,62 \\
IP2 & 4,15 & & 0,87 & 0,63 \\
\hline Autovalor & 3 & 0,61 & 0,58 & \\
Número de itens & 41,57 & 3,05 & 3 & \\
\% Var. Explicada & 0,86 & 20,46 & 10,86 & \\
Alfa & 0,86 & 0,82 & 0,83 & \\
Lambda 2 & 0,73 & 0,82 & 0,83 & \\
Carga mínima & 0,94 & 0,75 & 0,58 & \\
Carga máxima & 0,84 & 0,83 & 0,87 & \\
Carga média & 0,80 & 0,69 & \\
\hline
\end{tabular}


Pertencentes a todos os níveis hierárquicos da Corporação, com idade variando de 25 a 53 anos $(M=39,25$ e $D P=6,73)$, sendo a maioria casada $(64,5 \%)$, católica $(47,5 \%)$ e com 16,24 anos de serviço em média $(D P=$ $8,35)$. Essa foi uma amostra não probabilística, tendo participado as pessoas que concordaram em colaborar com a pesquisa.

\section{Instrumentos e Procedimentos}

Os participantes responderam aos mesmos instrumentos e os mesmos procedimentos de aplicação foram realizados, conforme descrito no Estudo 1.

\section{Análise dos Dados}

A análise fatorial confirmatória (AFC) foi realizada com a utilização do software AMOS 18. Para confirmar a estrutura latente existente, buscou-se especificar as relações entre as variáveis, prioritariamente, levando-se em consideração os índices de ajuste para decidir se os dados se adequam ao modelo. Em caso de índices satisfatórios, conclui-se que o modelo se ajusta aos dados.

Para tanto, foram considerados os seguintes índices com seus valores de referência, de acordo com Marôco (2010) e Roussel et al. (2002):

- $\quad \chi^{2} / g l\left(1 \leq \chi^{2} / g l \leq 5\right)$ - permite medir o grau de parcimônia absoluta do modelo;

- SRMR (Standardized Root Mean Square Residual) representa a diferença entre a correlação normalizada observada e a correlação previsível $(<0,10)$.

- CFI (Comparative Fit Index) - mede a diminuição relativa da falta de ajustamento $(>0,90)$;

- RMSEA (Root Mean Square Error of Approximation) representa a diferença média por graus de liberdade esperado na população total, de maneira a compensar a melhoria, potencial, do ajuste do modelo pela simples adição de mais parâmetros $(<0,10)$.

\section{Resultados}

Dois modelos foram analisados para aferir a qualidade do ajuste dos dados. O primeiro avaliou um modelo unidimensional (teste de Harman, conforme Malhotra, Sung, \& Ashutosh, 2006), comumente empregado para estudos que buscam evidências de validação de instrumentos de medida; o segundo pesquisou um modelo com os três fatores oriundos da AFE, de acordo com o modelo proposto por Cameron (2004).
O Modelo 1 (unidimensional) não apresentou ajustes satisfatórios, o que levou à sua rejeição, reforçando os estudos que evidenciam que a identidade é um construto multidimensional. Diante disso, foi testado o Modelo 2, que apresentou índices muito satisfatórios de ajuste, sem a necessidade de reespecificarão do modelo de medida. Os índices de ajuste dos três modelos são mostrados na Tabela 4.

A confiabilidade, no Estudo 2, foi medida pelo Rho (@) de deJöreskog, que se apresenta como a parte da variância dos fatores compostos compartilhada pelos itens que medem esse fator, diferindo-se do alfa de Cronbach que sofre influência da quantidade de itens. Representam, assim, a consistência interna dos itens reflexivos do fator, indicando o grau em que esses itens são manifestações do fator latente (Jöreskog, 1971), sendo considerados adequados valores superiores a 0,7 . O valor do Rho, de Jöreskog, mostrou ótima consistência interna para todas as dimensões, conforme Tabela 4.

Buscou-se, ainda, verificar a validade convergente. Para verificar essa medida, Fornell e Larcker (1981) utilizam o Rho de validade convergente $\left(\varrho_{\mathrm{vc}}-\mathrm{Rho}_{\mathrm{vc}}\right)$, calculado pela variância média extraída (VEM) do fator. Valores superiores a 0,5 são indicativos de validade convergente, o que foi satisfeito para todos os fatores. Além disso, encontraram-se valores de correlações múltiplas ao quadrado próximas ou superiores a 0,5 , o que fornece prova complementar da validade convergente (Bagozzi \& Yi, 1988). Os pesos fatoriais foram todos significativos e fortes $(\lambda i>0,6 ; p<0,001)$.

Foi testada, por último, a validade discriminante entre as dimensões, que ocorre quando as variâncias médias extraídas (VME's) dos fatores forem maiores ou iguais ao quadrado das correlações entre esses fatores (Rhovc $>r^{2}$ ), conforme observam Fornell e Larcker (1981). Sendo confirmada, no presente estudo, para o Modelo 2.

A Tabela 5 apresenta o resumo das qualidades psicométricas e a Figura 2 exibe a representação gráfica do Modelo 2.

\section{Discussão}

O presente artigo procurou adaptar e reunir evidências psicométricas de adequação da Escala Trifatorial da Identidade social (ETIS) ao contexto profissional brasileiro, representando a própria identidade profissional, conhecendo sua validade fatorial, validade convergente e discriminante, além de comprovar sua homogeneidade e consistência interna. Os dois estudos 
Tabela 4

Índices de Ajustamento dos Modelos de Medida conforme Modelos 1 e 2 da ETIS

\begin{tabular}{|c|c|c|c|}
\hline $\begin{array}{l}\text { Amostra } \\
N=451\end{array}$ & & $\begin{array}{c}\text { Modelo } 1 \\
\text { Unidimensional } \\
\end{array}$ & $\begin{array}{c}\text { Modelo } 2 \\
3 \text { Dimensões }\end{array}$ \\
\hline \multirow{5}{*}{$\begin{array}{l}\text { Índices } \\
\text { Absolutos }\end{array}$} & $\chi / g l$ & 23,82 & 2,67 \\
\hline & $\chi^{2} ; g l$ & 643,$26 ; 27$ & 64,$01 ; 24$ \\
\hline & $p$ & 0,000 & 0,000 \\
\hline & GFI (AGFI) & $0,73(0,55)$ & $0,97(0,94)$ \\
\hline & SRMR & 0,1525 & 0,038 \\
\hline \multirow{2}{*}{ Índices Relativos } & CFI & 0,63 & 0,98 \\
\hline & TLI & 0,51 & 0,96 \\
\hline Índices de Discrepância Populacional & $\begin{array}{c}\text { RMSEA } \\
\text { (Lo90;Hi90) }\end{array}$ & $\begin{array}{c}0,225 \\
(0,210 ; 0,240)\end{array}$ & $\begin{array}{c}0,061 \\
(0,043 ; 0,079)\end{array}$ \\
\hline \multirow{2}{*}{ Índices de Parcimônia } & PCFI & 0,47 & 0,65 \\
\hline & PGFI & 0,44 & 0,52 \\
\hline \multirow{3}{*}{$\begin{array}{l}\text { Índices baseados na Teoria da } \\
\text { Informação }\end{array}$} & AIC & 679,26 & 106,01 \\
\hline & ECVI & 1,51 & 0,24 \\
\hline & CAIC & 771,26 & 213,35 \\
\hline
\end{tabular}

Tabela 5

Confiabilidade e Validade das Dimensões conforme Modelo 2 da ETIS

Confiabilidade e Validade Convergente do Modelo 2

Pesos Fatoriais

( $t$-valor)

Dimensão Centralidade: $\varrho=0,87$; Rhovc $=0,70, t=88,50>1,96$

IP17 - Ser um policial é um importante reflexo de quem eu sou.

$0,78(71,56)$

IP3 - Em minha vida diária, eu frequentemente penso sobre o que significa ser um policial.

$0,68(78,27)$

IP2 - Ser um policial é uma parte importante de quem eu sou.

$0,81(74,98)$

Dimensão Afeto: $\varrho=0,87$; Rhovc $=0,70, t=34,00>1,96$

IP18 - Só de pensar sobre o fato de que eu sou um policial às vezes me dá sentimentos ruins.

$0,74(33,65)$

IP10 - Eu não me sinto bem em ser um policial.

$0,71(34,67)$

IP6 - Eu frequentemente me arrependo de ser um policial.

$0,81(35,86)$

Dimensão Laços: $\varrho=0,91$; Rhovc $=0,77, t=89,68>1,96$

IP14 - Eu tenho muito em comum com os demais policiais.

$0,83(75,46)$

IP13 - Eu sinto fortes vínculos com outros policiais.

$0,89(74,27)$

IP12 - Eu sinto que me ajusto bem quando estou entre policiais.

$0,70(86,38)$

Validade Discriminante do Modelo 2

\begin{tabular}{lccc}
\hline & Centralidade & Afeto & Laços \\
\hline Centralidade & $\mathbf{0 , 7 0}$ & & \\
Afeto & 0,12 & $\mathbf{0 , 7 0}$ & \\
Laços & 0,46 & 0,04 & $\mathbf{0 , 7 7}$ \\
\hline
\end{tabular}




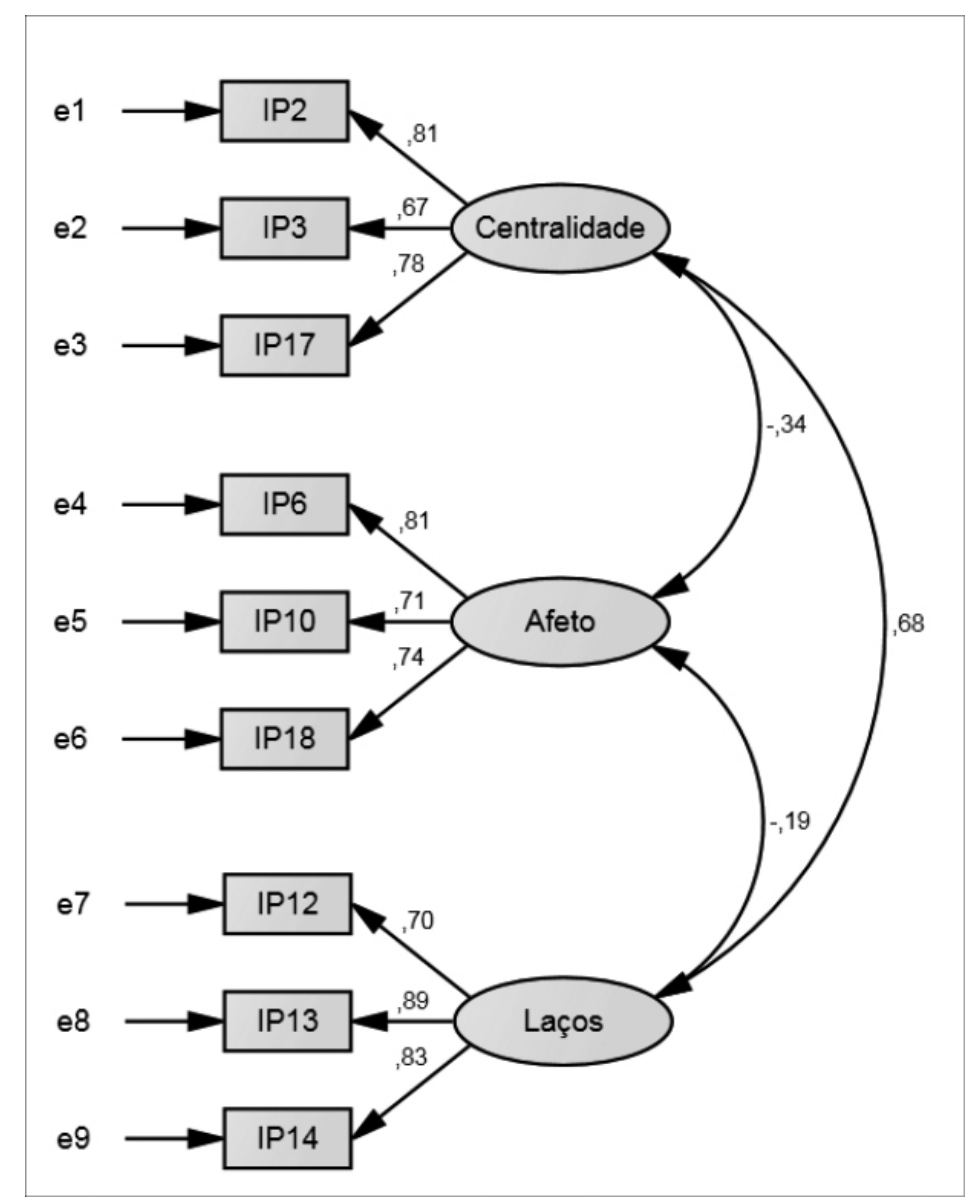

Figura 2. Modelo Trifatorial da Identidade Social.

realizados empregaram um instrumento simples e autoaplicável, que utiliza apenas lápis e papel, em que os itens isoladamente ou no conjunto apresenta, qualidades métricas satisfatórias, o que aponta para seu uso em pesquisas futuras.

Conforme especificado anteriormente, a identidade social é um construto relevante para verificar como o indivíduo se vincula de maneira cognitiva e afetiva a um ou mais grupos de pertença. Essa definição abrange os efeitos da natureza e a importância subjetiva dos indivíduos em suas relações interpessoais, ainda que se admita os limites da definição e a complexidade da forma como o indivíduo se enxerga em relação ao ambiente físico e social (Tajfel, 1978, 1982).

Os estudos prévios mostraram que a identidade social tem sido mensurada por diferentes instrumentos (Brown et al., 1986; Cameron, 2004; Nascimento et al., 2015; Obst \& White, 2005). No entanto, parte desses instrumentos de medida não apresentaram uma teoria que servisse de base para sua construção ou não levaram em consideração a dimensionalidade do construto, como, por exemplo, a escala de identidade de grupo de Brown et al. (1986).

Nesse sentido, confia-se oferecer uma contribuição importante à temática, ao se disponibilizar para o contexto brasileiro a adaptação de um instrumento específico para medir identidade social, que parte de uma teoria robusta, a teoria da identidade social (Tajfel, 1979). Até porque, medidas como essa são escassas na literatura brasileira (Nascimento, 2010; Nascimento et al., 2013; Nascimento, 2014), o que a torna útil e apropriada (Cameron \& Lalonde, 2001; Ellemers et al., 1999) para estudos futuros, seja no contexto do trabalho e organizacional, de grupos e equipes.

A ETIS contempla os conceitos essenciais que estruturam a TIS, a saber: categorização social, construto cognitivo, identificação social, de natureza afetiva e comparação social, que avalia o vínculo com o grupo de pertença (Tajfel, 1979; Tajfel \& Turner, 1979). Assim, o fator Centralidade representa a proeminência 
cognitiva de uma dada associação de grupo; o fator Afeto com o grupo de pertença, que se refere a avaliação emocional da afiliação a determinado grupo de pertença; e o fator Laços com o grupo de pertença, que versa sobre a percepção de similaridade e ligações com outros membros do grupo (Cameron, 2004; Obst \& White, 2005). Esses fatores contemplam os níveis afetivo e cognitivo em que se processa a identidade profissional (Machado, 2003).

Os achados previamente descritos sugerem que a versão brasileira da ETIS, composta por 9 itens, é parcimoniosa, descrevendo três fatores que corroboram a estrutura encontrada no estudo original (Cameron, 2004). Destaca-se que a estrutura da ETIS emergiu da análise fatorial exploratória (análise dos componentes principais - PCA) e foi suportada pelo emprego da análise fatorial confirmatória (máxima verossimilhança - ML), em que os indicadores apresentaram índices de ajuste coerentes com os valores recomendados na literatura (Marôco, 2010). Bem como, a ETIS mostrou evidencias de validade convergente e discriminante para a amostra utilizada (Fornell \& Larcker, 1981; Hair et al., 2009; Marôco, 2010), como aconteceu com a artigo original (Cameron, 2004).

No que se refere aos indicadores de consistência interna, os alfas de Cronbach observados apresentaram-se com valores superiores ao recomendado na literatura (0,70; Pasquali, 2003). A ETIS reteve nove itens do instrumento original. A perda de parte dos itens não ocasionou problemas vinculados ao objetivo do construto, mantendo uma variância explicada de $72,86 \%$, com índices de confiabilidade (Laços $\alpha=$ 0,86 ; Afeto $\alpha=0,82$; Centralidade $\alpha=0,83$ ), superiores à média do estudo original de Cameron (2004) para as três dimensões (Laços $\alpha=0,79$; Afeto $\alpha=$ $0,79$; Centralidade $\alpha=0,73)$, superior à média encontrada no estudo de Obst e White (2005) (Laços $\alpha=$ $0,84$; Afeto $\alpha=0,81$; Centralidade $\alpha=0,74)$. Além disso, o próprio Cameron (2004) sugere a utilização do instrumento em versões reduzidas, aumentando sua parcimônia e equilibrando o número de itens para cada dimensão.

Os indicadores do estudo exploratório (AFE) e do estudo confirmatório (AFC) demonstraram adequações psicométricas satisfatórias, com índices de confiabilidades aceitáveis, medidos pelos indicadores: Alpha de Cronbach, Lambda 2 de Guttman e Rho de Jöreskog. A consistência interna do Estudo 2, medida pelo Rho de Jöreskog, adicionada à consistência encontrada no Estudo 1, justificam a utilização dessa medida no contexto da pesquisa, quando o propósito for conhecer a identidade profissional.

A medida de identidade social aplicada ao ambiente profissional operacionalizou-se pela medida trifatorial construída e validada por Cameron (2004) com base na teoria da identidade social (Tajfel, 1978). As evidências encontradas pelo estudo original (Cameron, 2004) e por estudos confirmatórios (Obst \& White, 2005) evidenciaram a estrutura de três fatores, o que soluciona o problema da dimensionalidade do construto. Os benefícios potenciais de um modelo multidimensionalde medição, que se alicerça em três fatores, associada à identificação social, em contrapartida a uma forma unidimensional, encontra-se na riqueza de detalhes fornecidos ao se examinar cada uma das dimensões subjacentes de maneira separadas (Obst \& White, 2005).

O exame da estrutura trifatorial permite, ainda, avaliar o nível de integração entre cada dimensão subjacente, podendo esse resultado diferir ao se compararem grupos distintos, refletindo informações potencialmente reveladoras acerca do grau de associação entre o componente afetivo, a consciência cognitiva e os laços com outros membros, que compõem a identidade social para uma associação junto ao grupo específico (Cameron, 2004; Obst \& White, 2005). Além disso, conforme Obst e White (2005), a escala trifatorial permite o exame da participação dos indivíduos em grupos variados de forma simultânea. O que possibilita a investigação das diferenças médias entre os grupos sobre as dimensões separadas, além da realização de ilações se o tipo de relação com o qual os elementos da identidade social (ou seja, afetivos, cognitivos, e os laços com outros membros) estão produzindo diferenças nos níveis gerais de identificação social.

\section{Considerações Finais}

Em síntese, os achados previamente descritos dão conta de evidências de que a ETIS é parcimoniosa, válida e precisa, suprindo uma lacuna no contexto brasileiro no que se refere a uma medida de identidade social, que pode ser aplicada em diversos contextos, como no caso deste artigo, atrelada ao contexto profissional, apresentando-se como um novo e importante instrumento de medida no contexto brasileiro, sobretudo para a gestão de organizações.

Parece pertinente nesse momento pontuar as limitações potenciais dos estudos realizados. No caso, ressalta-se o fato de as amostras terem sido de conveniência (não probabilísticas), considerando profissionais 
de segurança pública. As amostras de conveniência demandam, entretanto, a replicação da escala em outros contextos profissionais, como, por exemplo, profissionais de outras áreas do setor público, bem como, do setor privado. Resta, no entanto, ponderar que se pretendia unicamente contar com evidências de adequação psicométrica da ETIS, avaliando a possibilidade de identificar uma estrutura trifatorial.

Pesquisas futuras são recomendadas, embora a estrutura da ETIS apresente evidências psicométricas favoráveis. Nesse sentido, poderia ser pensada, como agenda, a possibilidade de conhecer sua validade de critério (concorrente e, principalmente, preditiva) e estabelecimento de uma rede nomológica, o que possibilitará um avanço na adequação dessa medida. Ademais, pode-se avaliar sua estabilidade temporal (teste-reteste) o que pode ser bastante oportuno, analisando a magnitude, sua flutuação com o tempo ou eventos históricos identificados (Pasquali, 2012).

Por fim, recomenda-se o uso da ETIS no âmbito organizacional (Kira \& Balkin, 2014; Nascimento et al., 2015) atrelada a medidas que enfatizem aspectos da cultura organizacional (Nascimento, 2014), desempenho (Mitchell et al., 2011; VanKnippenberg \& Schippers, 2007) e criatividade (Brickson, 2013), entre outras. Estes e outros esforços podem ser verdadeiramente úteis para melhor se compreender a mensuração da identidade social no contexto profissional, representando a própria identidade profissional.

\section{Referências}

Álvaro, J. L., \& Garrido, A. (2006) Psicologia social: Perspectivas psicológicas e sociológicas. São Paulo: McGraw Hill.

Ashforth, B. E. (2001). Role transitions in organizational life: An identity-based perspective. Academy of Management Review, 26(4), 670-672. Recuperado de http://www.jstor.org/stable/3560250

Bagozzi, R. P., \& Yi, Y. (1988). On the evaluation of structural equation models. Journal of the Academy of Marketing Science, 16(1), 74-94. doi: 10.1007/ $\mathrm{BF} 02723327$

Baugnet, L. (1998). L'identitésociale. Dunod: Paris.

Boatswain, S., \& Lalonde, R. (2000). Social identity and preferred ethnic/racial labels for blacks in Canada. Journalof Black Psychology, 26, 216-234. doi: 10.1177/0095798400026002006
Brandão, C. R. (1990). Identidade e etnia: Construção da pessoa e resistência cultural. São Paulo: Brasiliense.

Brickson, S. L. (2013). Athletes, best friends, and social activists: An integrative model accounting for the role of identity in organizational identification. Organization Science 24(1), 226-245. doi: 10.1287/ orsc. 1110.0730

Brislin, R. W. (1970). Back-translation for cross-cultural research. Journal of Cross-Cultural Psychology, 1(3), 185-216. doi: 10.1177/135910457000100301.

Brown, R., Condor, S., Mathews, A., Wade, G., \& Williams, J. (1986). Explaining intergroup differentiation in an industrial organization. Journal of Occupational Psychology, 59, 279-304. doi: 10.1111/ j.2044-8325.1986.tb00230.x

Cameron, J. E. (2004). A three-factor model of social identity. Self and Identity, 3(3), 239-262. doi: 10.1080/13576500444000047.

Cameron, J. E., \& Lalonde, R. (2001). Social identification and gender related ideology in women and men. British Journal of Social Psychology, 40, 59-77. doi: 10.1348/014466601164696

Cassepp-Borges, V., Balbinotti, M. A., \& Teodoro, M. L. M. (2010). Tradução e validação de conteúdo: Uma proposta para a adaptação de instrumentos. Em L. Pasquali, et al. Instrumentação Psicológica: fundamentos e práticas. Porto Alegre: Artmed, 506-520.

Cha, E. S., Kim, K. H., \& Erlen, J. A. (2007). Translation of scales in cross-cultural research: Issues and techniques. Journal of Advanced Nursing, 58(4), 386395. Recuperado de http://www.ncbi.nlm.nih. gov/pubmed/17442038

Corley, K. G., \& Gioia, D. A. (2004). Identity ambiguity and change in the wake of a corporate spin-off. Administrative Science Quarterly, 49(2), 173-208. doi: $10.2307 / 4131471$

Deaux, K. (1996). Social Identification. Em E. Higgins \& A. Kruglanski (Eds.), Social Psychology: Handbook of basicprinciples (pp. 777-798). New York: Guilford.

Dubar, C. (2005). A Socialização: Construcão de identidades sociais e profissionais. (Silva, A. S. M., Trad.). São Paulo: Martins Fontes.

Dubar, C. (2009). A crise das identidades: A interpretação de uma mutação. (Barros, M. A. L., Trad.). São Paulo: EDUSP. 
Ellemers, N., Kortekaas, P., \& Ouwerkerk, J. (1999). Self-categorisation, commitmentto the group and group self esteem as related but distinct aspects of social identity. European Journal of Social Psychology, 29, 371-389. doi: 10.1002/ (SICI)1099-0992(199903/05)29:2/3<371::AIDEJSP932>3.0.CO;2-U

Ellemers, N., Spears, R., \& Doosje, B. (2002). Self and Social Identity. Annual Review of Psychology, 53, 161186. doi: $0.1146 /$ annurev.psych.53.100901.135228

Fernandes, M. E. R., Marques, A. L., \& Carrieri, A. P. (2009). Identidade organizacional e os componentes do processo identificatório: Uma proposta de integração. Cadernos EBAPE.BR, 7, 688-703. doi: 10.1590/S1679-39512009000400011

Festinger, L. (1971). Théoriedesprocessus de comparisonsociale. Em C. Faucheux \& S. Moscovici (Eds.). Psychologie social et héorique e texpérimentale. Paris: Mouton.

Fitzgerald, A., \& Teal, G. (2003). Health reform, professional identity and occupational sub- cultures: The changing interprofessional relations between doctors and nurses. Contemporary Nurse 16(1-2), 9-19. doi: 10.5172/conu.16.1-2.9

Fornell, C., \& Larcker, D. F. (1981). Evaluating structural equation models with unobservable variables and measurement error. Journal of Marketing Research, 18(1), 39-50. Recuperado de http://www. google.com.br/url?q=https:/ / facultygsb.stanford. edu/larcker/PDF $/ 6 \% 2520$ Unobservable $\% 2520 \mathrm{~V}$ ariables.pdf\&sa $=$ U\&ei $=\mathrm{Jk} 2 \mathrm{VdzzKYGlsQXOmor}$ oCA\&ved $=0 \mathrm{CBkQFjAA \& usg=AFQjCNFRfUzw}$ Ix1SRd6baQsJzSi 9jAF9A

Galinkin, A. L., \& Zauli, A. (2011). Identidade Social e Alteridade. Em C. V. Torres \& E. R. Neiva (Eds.). Psicologia social: principais temas e vertentes. Porto Alegre: Artmed.

Gurin, P., \& Townsend, A. (1986). Properties of gender identity and their implications for gender consciousness. British Journal of Psychology, 25, 139-148. doi: 10.1111/j.2044-8309.1986.tb00712.x

Gurin, P., \& Markus, H. (1989). The cognitive consequences of gender identity. Em S. Skevington \& D. Baker (Eds.). The Social Identity of Women. Beverly Hills, CA: Sage Publications.
Hair, J. F., Black, W. C., Babin, B. J., Anderson, R. E., \& Tatham, R. L. (2009). Análise multivariada de dados. (A. S. Sant'Anna, Trad.). Porto Alegre: Bookman.

He, H., \& Brown, A. D. (2013). Organizational identity and organizational identification: A review of the literature and suggestions for future research. Group and Organization Management, 38(1), 3-35. doi: $10.1177 / 1059601112473815$

Hernandez-Nieto, R. (2002). Contributions to statistical analysis. Mérida, España: Los Andes University Press.

Hinkle, S., Taylor, L., Fox-Cardamone, D., \& Crook, K. (1989). Intragroup identification and intergroup differentiation: A multicomponent approach. British Journal of Social Psychology, 28, 305-317. doi: 10.1111/j.2044-8309.1989.tb00874.x

Hirst, G., van Dick, R., \& van Knippenberg, D. (2009). A social identity perspective on leadership and employee creativity. Journal of Organizational Behavior, 30(7), 963-982. doi: 10.1002/job.600

Hogg, M. A., \& Terry, D. J. (2000). Social identity and self-categorization processes in organizational contexts. Academy of Management Review, 25(1), 121140. doi: 10.5465/AMR.2000.2791606

Howard, J. A. (2000). Social psychology of identities. Annual Review of Sociology, 26, 367-393. doi: 10.1146/annurev.soc.26.1.367

Jöreskog, K. G. (1971). Statistical analysis of sets of congeneric tests. Psychometrika, 36(4), 109-133. doi: 10.1007/BF02291393

Kelly, C. (1988). Intergroup differentiation in a political context. British Journal of Social Psychology, 27, 319332. doi: 10.1111/j.2044-8309.1988.tb00835.x

Kira, M., \& Balkin, D. B. (2014). Interactions between work and identities: Thriving, withering, or redefining the self? Human Resource Management Review, 24(2), 131-143. doi: 10.1016/j.hrmr.2013.10.001

Landis, J. R., \& Koch, G. G. (1977). The measurement of observer agreement for categorical data. Biometrics, 33(1), 159-174. doi: 10.2307/2529310

Luhtanen, R., \& Crocker, J. (1992). A collective self-esteem scale: Self-evaluation of one's social identity. Personalityand Social Psychology Bulletin, 18, 302-318. doi: 10.1177/0146167292183006 
Lyra, W. S., Silva, E. C., Araújo, M. C. U., Fragoso, W. D., \& Veras, G. (2010). Classificação periódica: Um exemplo didático para ensinar análise de componentes principais. Química Nova, 33(7), 1594-1597. doi: 10.1590/S0100-40422010000700030

Machado, H. V. (2003). A identidade e o contexto organizacional: Perspectivas de análise. Revista de Administração Contemporânea. 7(spe), 51-73. doi: 10.1590/S1415-65552003000500004

Madjar, N., Greenberg, E., \& Chen, Z. (2011). Factors for radical creativity, incremental creativity, and routine, noncreative performance. Journal of Applied Psychology, 96(4), 730-743. doi: 10.1037/ a0022416

Malhotra, N. K., Sung K.S., \& Ashutosh, P. (2006). Common method variance in IS research: A comparison of alternative approaches and a reanalysis of past research. Management Science, 52(12), 18651883. doi: $10.1287 /$ mnsc. 1060.0597

Marôco, J. (2010). Análise de equações estruturais: Fundamentos teóricos, software e aplicações. Pero Pinheiro: Report Number.

Marôco, J. (2011). Análise estatística com o SPSS Statistics. 5a. Ed. Pero Pinheiro: Report Number.

Mitchell, R., Parker, V., \& Giles, M. (2011). When do interprofessional teams succeed? Investigating the moderating roles of team and professional identity in interprofessional effectiveness. Human Relations, 64(10), 1321-1343. doi: $10.1177 / 0018726711416872$

Nascimento, T. N. (2014). Desempenho profissional por competências: Relacõoes com valores, práticas e identidade no serviço policial (Tese de doutorado não publicada). Programa de Pós-graduação em Administração, Universidade de Brasília.

Nascimento, T. G. (2010). Polícia - Uma identidade em discussão: Construção, validação e aplicação de um instrumento (Dissertação de mestrado). Programa de Pós-graduação em Psicologia Social, do Trabalho e das Organizações. Universidade de Brasília, Brasilia.

Nascimento, T. G., Torres, C. V., Souza, E. C. L., Nascimento, D. A., \& Adaid-Castro, B. G. (2013). Identidade no trabalho e a influência de aspectos sociodemográficos: Um estudo da diferença entre grupos de policiais militares do Distrito Federal.
Revista Brasileira de Segurança Pública, 7, 90-117. Recuperado de http://revista.forumseguranca.org. br/index.php/rbsp/article/view/320/152

Nascimento, T. G., Torres, C. V., \& Castro, B. G. A. (2015). Escala de identidade profissional policial militar (EIPPM): Evidências de validade fatorial e preditiva. Revista Pensamento Contemporâneo em Administração, 9(2), 142-166. doi: 10.12712/rpca. v9i2.462

Neiva, E. R., Abbad, G., \& Tróccoli, B. T. (2007). Roteiro para análise fatorial de dados. Manuscrito não publicado, Instituto de Psicologia, Universidade de Brasília, DF.

Nishii, L. H., \& Mayer, D. (2009). Do inclusive leaders help to reduce turnover in diverse groups? The moderating role of leader-member exchange in the diversity to performance relationship. Journal of Applied Psychology, 94(6), 1412-1426. doi: 10.1037/ a0017190

Obst, P. L., \& White, K. M. (2005). An exploration of the interplay between psychological sense of community, social identification and salience. Journal of Community and Applied Social Psychology, 15(2), pp. 127-135. doi: 10.1002/casp.813

Obst, P., Zinkiewicz, L., \& Smith, S. (2002). Sense of community in science fiction fandom, Part 1 : Understanding sense of community in an international community of interest. Journal of Community Psychology, 30(1), 87-103. doi: 10.1002/jcop.1052

Pasquali, L. (2003). Psicometria: Teoria dos testes na Psicologia e na Educação. Petrópolis, RJ: Vozes.

Pasquali, L. (2012). Análise Fatorial para pesquisadores. 1 ed. Brasília: LabPAM Editora.

Perreault, S., \& Bourhis, R. Y. (1999). Ethnocentrism, social identification, and discrimination. Personality and Social Psychology Bulletin, 25, 92-103. doi: 10.1177/0146167299025001008

Reade, C. (2001). Dual identification in multinational corporations: Local managers and their psychological attachment to the subsidiary versus the global organization. International Journal of $\mathrm{Hu}$ man Resource Management, 12(3), 405-424. doi: $10.1080 / 713769627$

Roussel, P., Durrieu, F., Campoy, E., \& Akremi, A. E. (2002), Méthodes d'équations structurelles: Rechercheet applications en gestion. Economica: Paris. 
Sainsanlieu, R. (1977). Identité au travail les effetsculturels de l'organisation. Paris: Presses de la Fondation Nationale de Sciences Politiques.

Sainsanlieu, R. (1995). L'identitéautravail: une expériencepartagée. Em J. Francfort et al. Les mondessociaux de l'entreprise. Paris: Sociologie Économique.

Spears, R., Doosje, B., \& Ellemers, N. (1999). Commitment and the context of social perception. Em N. Ellemers, R. Spears \& B. Doosje (Eds.), Social identity: Context, commitment, content (pp. 59-83). Oxford: Blackwell.

Tajfel, H. (1978). Differentiation between social groups: Studies in the social psychology of intergroup relations. New York: academic.

Tajfel, H. (1981). Human groups and social categories. Cambridge: Cambridge University Press.

Tajfel, H. (1982). Grupos humanos e Categorias sociais: Estudos em psicologia social. (L. Amâncio, Trad.). Vol. I, Lisboa, Livros Horizonte.

Tajfel, H. (1983). Grupos humanos e categorias sociais: Estudos em psicologia social. (L. Amâncio, Trad.). Vol. II, Lisboa: Livros Horizonte.

Tajfel, H., \& Turner, J. C. (1979). An integrative theory of intergroup conflict. Em W. G. Austin e S. Worchel
(Eds.). The social psychology of intergroup relations, Monterey, Brooks.

Torres, C. V., \& Pérez-Nebra, A. R. (2004). Diversidade cultural no contexto organizacional. Em J. C. Zanelli, J. E. Borges-Andrade \& A. V. B. Bastos, (Eds.). Psicologia, organizações e trabalho no Brasil. Porto Alegre: Artmed.

Turner, J. C. et al. (1987). Rediscovering the social group: $A$ self-categorization theory. Oxford: Basil Black-Well, 1987.

Vallerand, J. R. (1989). Versune mèthodologie de validation trans-culturelle de questionnaires psychologiques: Implications pour la recherche en langue fraçaise. Canadian Psychology, 30(4), 662-680. doi: $10.1037 /$ h0079856

Van der Zee, K., Atsma, N., \& Brodbeck, F. (2004). The influence of social identity and personality on outcomes of cultural diversity in teams. Journal of Cross-Cultural Psychology. v. 35 p. 283-303. doi: 10.1177/0022022104264123.

VanKnippenberg, D., \& Schippers, M. C. (2007). Work group diversity. Annual Review of Psychology, 58, 515541.doi:10.1146/annurev.psych.58.110405.085546

Recebido em: 13/07/2015 Reformulado em: 15/02/2016;07/03/2016

Aceito em: 28/03/2016 
Sobre os autores:

Thiago Gomes Nascimento é mestre em Psicologia Social, do Trabalho e das Organizações e doutor em Administração, ambos pela Universidade de Brasília, doutor em Ciências de Gestão pela Université d'Aix-Marseille, França, e professor do Instituto Superior de Ciências Policiais e do Centro Universitário IESB. Realizou pós-doutorado em Administração Pública no Centro de Administração e Políticas Públicas do Instituto Superior de Ciências Sociais e Políticas da Universidade de Lisboa, Portugal.

E-mail: tgn.1980@gmail.com

Eda Castro Lucas de Souza é doutora em Sociologia pela Faculdade Latino Americana de Ciências Sociais(FLASCO) e pela Universidade de Brasília, com pós-doutorado na Universidade Federal do Rio Grande do Sul, na Écoledes Hautes Etudes Commerciales de Montreal, Canadá, no CERGAM (Équipe management international - FEA), Université Paul Cézanne, Aix-Marseille III, e no Instituto Superior de Ciências Sociais e Políticas da Universidade de Lisboa, Portugal. É professora do Programa de Pós-Graduação em Administração da Universidade de Brasília.

E-mail: edalucas@gmail.com

Contato com os autores:

Thiago Gomes Nascimento

Universidade de Brasília - Campus Universitário Darcy Ribeiro, Prédio da FACE

Brasília - DF

CEP: 70910-900

Endereço Residencial: Rua 18 Norte, Lote 07, Apartamento 102

Águas Claras, Brasília-DF, Brasil

CEP: $71.910-720$

Eda Castro Lucas de Souza

Universidade de Brasília - Campus Universitário Darcy Ribeiro, Prédio da FACE

Brasília - DF

CEP: 70910-900,

Endereço Residencial: SQN, 116, Bloco I, ap. 208

Asa Norte, Brasilia-DF, Brasil

CEP: 70773-090 